\section{(2) OPEN ACCESS}

\title{
Epidemiology and outcomes of gastroparesis, as documented in general practice records, in the United Kingdom
}

\author{
Yizhou Ye (D) , ${ }^{1}$ Baoguo Jiang, ${ }^{2}$ Sudhakar Manne, ${ }^{2}$ Peter L Moses, ${ }^{3}$ Cristina Almansa, ${ }^{3}$ \\ Dimitri Bennett, ${ }^{1,4}$ Paul Dolin, ${ }^{5}$ Alexander C Ford ${ }^{6,7}$
}

- Additional material is published online only. To view please visit the journal online (http://dx.doi.org/10.1136/ gutjnl-2020-321277).

For numbered affiliations see end of article.

\section{Correspondence to} Dr Yizhou Ye, Global Evidence and Outcomes, Takeda Pharmaceutical Co Ltd, Cambridge 02139, Massachusetts, USA; james.ye@takeda.com

Received 31 March 2020 Revised 6 May 2020 Accepted 7 May 2020 Published Online First 3 June 2020

\section{Linked}

- http://dx.doi.org/10.1136/ gutjnl-2020-322140

\section{Check for updates}

(C) Author(s) (or their employer(s)) 2021. Re-use permitted under CC BY-NC. No commercial re-use. See rights and permissions. Published by BMJ.

To cite: Ye $Y$, Jiang $B$,

Manne $S_{\text {, et al. Gut }}$

2021:70:644-653

\begin{abstract}
Objective To generate real-world evidence for the epidemiology of gastroparesis in the UK, we evaluated the prevalence, incidence, patient characteristics and outcomes of gastroparesis in the Clinical Practice Research Datalink (CPRD) database.

Design This was a retrospective, cross-sectional study. Prevalence and incidence of gastroparesis were evaluated in the CPRD database, with linkage to Hospital Episodes Statistics Admitted Patient Care and Office for National Statistics mortality data. Prevalence and incidence were age and sex standardised to mid-2017 UK population estimates. Descriptive analyses of demographics, aetiologies, pharmacological therapies and mortality were conducted.

Results Standardised prevalence of gastroparesis, as documented in general practice records, was 13.8 (95\% Cl 12.6 to 15.1 ) per 100000 persons in 2016, and standardised incidence of gastroparesis rose from 1.5 (95\% Cl 1.1 to 1.8) per 100000 person-years in 2004 to $1.9(95 \% \mathrm{Cl} 1.4$ to 2.3$)$ per 100000 person-years in 2016. The most common disease aetiologies were idiopathic (39.4\%) and diabetic gastroparesis (37.5\%), with a similar distribution of type 1 and type 2 diabetes among the $90 \%$ who had type of diabetes documented. Patients with diabetic gastroparesis had a significantly higher risk of mortality than those with idiopathic gastroparesis after diagnosis (adjusted HR 1.9, 95\% Cl 1.2 to 3.0). Of those with gastroparesis, $31.6 \%$ were not offered any recognised pharmacological therapy after diagnosis.

Conclusion This is, to our knowledge, the first population-based study providing data on epidemiology and outcomes of gastroparesis in Europe. Further research is required to fully understand the factors influencing outcomes and survival of patients with gastroparesis.
\end{abstract}

\section{INTRODUCTION}

Gastroparesis is a motility disorder characterised by the presence of chronic upper GI symptoms and delayed gastric emptying in the absence of mechanical obstruction. ${ }^{1}$ Established risk factors include, but are not limited to, the presence of diabetes, a history of abdominal or oesophageal surgery, increasing age, and use of alcohol and tobacco. ${ }^{2-4}$ Cardinal symptoms and signs for gastroparesis include early satiety, upper abdominal

\section{Significance of this study}

What is already known on this subject?

- Epidemiological data for gastroparesis are sparse and limited to studies performed in the USA.

- Further studies are required to evaluate the impact and unmet need of gastroparesis in different populations outside of the USA.

What are the new findings?

- During 2016, the overall period prevalence of diagnosed gastroparesis was $13.8(95 \% \mathrm{Cl} 12.6$ to 15.1) per 100000 persons in the UK.

- Significant differences in prevalence were observed both across individual countries within the UK and within individual regions of England.

- Idiopathic gastroparesis was the leading aetiology recorded in the Clinical Practice Research Datalink (39.4\%), although the proportion with diabetic gastroparesis was similar.

How might it impact on clinical practice in the foreseeable future?

- Our findings suggest a degree of uncertainty regarding best practice or therapeutic options for patients with gastroparesis among healthcare professionals in the UK.

- This represents an opportunity for the education of healthcare providers and development of robust clinical guidelines to ensure effective disease management.

- Insights from our study will provide important guidance for clinicians and policy-makers when considering diagnostic approaches for gastroparesis and support future clinical practice, education and decision-making with respect to gastroparesis in the UK.

pain, nausea, vomiting, persistent anorexia and postprandial fullness; these symptoms are generally chronic with episodic exacerbations. ${ }^{5}$ Increasing symptom severity may be associated with detrimental effects on patients' quality of life, as well as coexistent anxiety and depression, ${ }^{46}$ and results in increased morbidity and mortality. ${ }^{7}$ The impact 
of gastroparesis on daily life is well documented both in terms of deteriorating patient quality of life and productivity, and the direct and indirect economic burdens placed on healthcare providers and society. ${ }^{89}$ The impact of gastroparesis is such that, in one study, patients were willing to accept a median $13.4 \%$ risk of death to cure their symptoms using a hypothetical medication. ${ }^{10}$

Despite these detrimental effects, epidemiological data on this disease are limited, and most studies have been conducted in referral settings. ${ }^{11-14}$ The only true population-based epidemiological study, from Olmsted County, Minnesota, USA, estimated the standardised prevalence of gastroparesis to be 24.2 per 100 000 persons and the standardised incidence to be 6.3 per 100 000 person-years. ${ }^{7}$ In this study, gastroparesis was more common in women than in men. ${ }^{7}$ However, owing to the relatively homogeneous local population, findings from Olmsted County may not accurately reflect the entire US population or populations of other countries, ${ }^{15} 16$ such as those in the UK. Furthermore, as there is considerable overlap between the symptoms of gastroparesis and functional dyspepsia, ${ }^{17}$ differences in payment systems and management guidelines between the USA and the UK may affect the diagnosis and reporting of gastroparesis. ${ }^{4}{ }^{41} 19$ In addition, the prevalence of some of the main risk factors for gastroparesis, such as diabetes, differ between the general populations of the USA and the UK. ${ }^{2021}$

The findings of region-specific US studies, therefore, provide limited insights into the epidemiology of gastroparesis in the UK and, correspondingly, there remains a paucity of communitybased data for gastroparesis both in the UK and Europe overall. To mitigate this deficit in knowledge, we conducted an observational epidemiological study that evaluated the prevalence and incidence of diagnosed gastroparesis in the UK general population, using electronic health records (EHRs) from the Clinical Practice Research Datalink (CPRD) database. We also examined the demographics, clinical characteristics, potential aetiologies and therapies offered to UK patients with gastroparesis.

\section{METHODS}

\section{Study design and data source}

This retrospective cross-sectional study was conducted in the UK CPRD database. The CPRD is a source of real-world data providing a longitudinal, representative UK population health data set that encompasses over 35 million patient lives. This population-based, anonymised database stores fully coded patient EHRs from general practitioners (GPs) in a primary care setting and covers more than 11.3 million patients from 674 general practices in the UK. ${ }^{22}$ With 4.4 million active patients meeting quality criteria, the CPRD covers approximately $7 \%$ of the UK population. ${ }^{23}$ Patients broadly represent the UK general population and, for over half of patients, the amount of available data is increased through linkage with data sets from secondary care, disease-specific cohorts and mortality records. ${ }^{23}$ For this study, CPRD primary care data with linkage to the Hospital Episodes Statistics (HES) for Admitted Patient Care data were used, ${ }^{24}$ along with UK Office for National Statistics (ONS) mortality data for vital status and death date. ${ }^{25}$

\section{Study population}

All patients registered in the CPRD for at least 1 day from 2000 to 2016 were included. Cases of gastroparesis were identified using Read codes (online supplementary table S1). Data entered into the CPRD are measured by two sets of data quality criteria, namely patient acceptability and 'up-to-standard' dates. The 'up-to-standard' date is a practice-based quality metric, which reflects the latest date at which practices meet CPRD's minimum quality criteria for research purposes. ${ }^{23}$

\section{Incidence}

Incidence was calculated during each calendar year from 2004 to 2016. The incident study population was all at-risk patients (ie, those with no previous diagnosis of gastroparesis) during each study year. Incident cases were therefore those patients in the incidence study population who had a new diagnosis of gastroparesis made during subsequent follow-up. At least 1 year of gastroparesis-free registration was required to minimise the possibility of misclassification of a prevalent case as incident, following registration with a new practice. ${ }^{26}$

\section{Prevalence}

A cross-sectional analysis was conducted for period prevalence through 2016 for the most up-to-date prevalence. The study population was all patients with at least 1 day of registration in 2016. Prevalent cases of gastroparesis were patients in the prevalent study population who had a diagnosis of gastroparesis on or before 31 December 2016.

\section{Study variables}

Study variables included patient demographics: age at diagnosis, sex, body mass index (BMI), and lifestyle factors for tobacco and alcohol intake; length of enrolment in the CPRD; follow-up for patient demographics (online supplementary table S2); comorbid conditions contributing to the Charlson Comorbidity Index; potential aetiologies; pharmacological therapies offered to patients with gastroparesis, including metoclopramide, domperidone, erythromycin, cisapride and prucalopride (online supplementary table S3).

Known causes of gastroparesis, including diabetes mellitus and other rarer causes such as Parkinson's disease, multiple sclerosis and scleroderma, were identified as potential underlying aetiologies, using all historical data prior to a diagnosis of gastroparesis being made..$^{27}$ Postsurgical gastroparesis was considered as the cause for patients who had undergone surgeries that may injure the vagus nerve, from up to 1 year prior to a diagnosis of gastroparesis, but who had no history of the aforementioned conditions. Similarly, drug-induced gastroparesis was considered the underlying aetiology for patients who had been using medication with the potential to delay gastric emptying, including selected opioid analgesics, calcium-channel blockers and anticholinergic agents (online supplementary table S4) within 90 days prior to a diagnosis of gastroparesis. The remaining patients with no record of any potential known cause of gastroparesis were classified as having an idiopathic aetiology.

\section{Statistical analysis}

Crude prevalence was calculated using the number of prevalent cases and the number of CPRD enrolees with at least 1 day of enrolment in 2016.

$$
\text { Prevalence }(\text { crude })=\frac{\text { All prevalent cases between } 1 \text { Jan and } 31 \text { Dec } 2016}{\text { All CPRD patients enrolled between } 1 \text { Jan and 31 Dec } 2016}
$$

For crude incidence, the entire CPRD population who did not have gastroparesis were considered at risk. At-risk person-time ended at the earliest occurrence of gastroparesis diagnosis, death (online supplementary text S2 and online supplementary table S5), eligibility discontinuation or the end of the study year.

Incidence $($ crude $)=\frac{\text { All incident cases between } 1 \text { Jan and } 31 \text { Dec of study year }}{\text { Sum of at }- \text { risk person }- \text { time between } 1 \text { Jan and } 31 \text { Dec of study year }}$ 


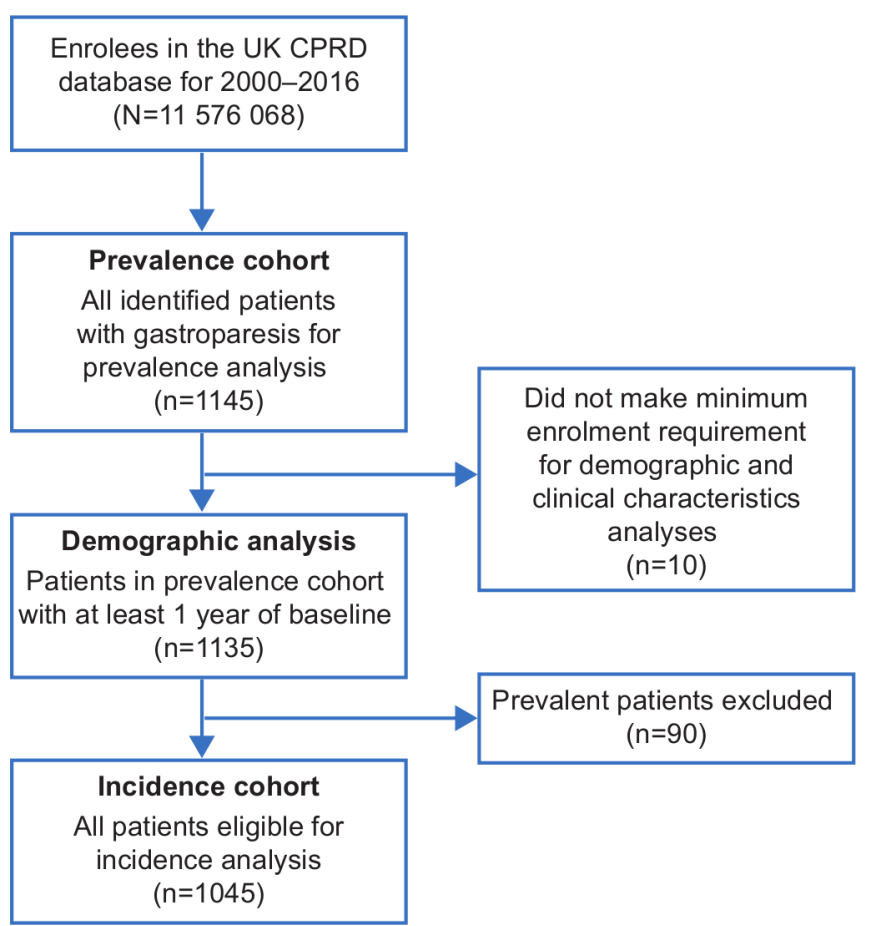

Figure 1 Flow chart of identification of patients with gastroparesis. CPRD, Clinical Practice Research Datalink.

Crude prevalence and incidence were age and sex standardised to the mid-2017 UK population estimate, based on national census data. A Poisson distribution was used to calculate 95\% CIs for prevalence and incidence.

Subgroup analyses were conducted for each sex, age group and geographical region using point prevalence on 1 July 2016. For chronic conditions like gastroparesis, period prevalence and point prevalence usually yield similar findings.

HES-ONS linked data are limited to patients in England. To minimise misclassification caused by missing data, overall survival was summarised for all patients with gastroparesis in England using the Kaplan-Meier product-limit life table method. The survival of diabetic gastroparesis versus idiopathic gastroparesis was compared using a multivariate Cox regression model to control for predictors in study variables. All available prediagnosis data were used to determine the medical history of each patient.

Data cleaning and analysis were conducted in SAS Enterprise Guide V.6.1 (Cary, NC, USA).

\section{Patient and public involvement}

Patients or the public were not involved in the design, conduct, reporting or dissemination plans of our research.

\section{RESULTS}

In total, 1145 cases of gastroparesis were identified for prevalence analysis, from a total of 11576068 individuals registered in the CPRD on or before 31 December 2016. In all, 1135 patients (99.1\%) were eligible for demographic analysis and 1045 patients $(91.3 \%)$ were eligible for incidence analysis (figure 1).

\section{Patient population}

Among the 1135 patients providing data for demographic analysis (table 1), the average duration of CPRD registration prior to

Table 1 Demographics and characteristics of patients with gastroparesis in the CPRD

\begin{tabular}{|c|c|}
\hline \multirow{2}{*}{ Study variable } & \multirow{2}{*}{$\begin{array}{l}\text { Patients with gastroparesis } \\
(n=1135)\end{array}$} \\
\hline & \\
\hline \multicolumn{2}{|l|}{ Sex, n (\%) } \\
\hline Female & $723(63.7)$ \\
\hline Male & $412(36.3)$ \\
\hline \multicolumn{2}{|c|}{ Age at first gastroparesis diagnosis, years } \\
\hline Mean (SD) & $50.6(20.1)$ \\
\hline \multicolumn{2}{|l|}{ Ethnicity, n (\%) } \\
\hline $\mathrm{n}$ & 608 \\
\hline White & $517(85.0)$ \\
\hline Asian & $74(12.2)$ \\
\hline Other & $17(2.8)$ \\
\hline \multicolumn{2}{|l|}{ Body weight, $\mathrm{kg}$} \\
\hline $\mathrm{n}$ & 709 \\
\hline Mean (SD) & $74.2(20.8)$ \\
\hline \multicolumn{2}{|l|}{$\mathrm{BMI}, \mathrm{kg} / \mathrm{m}^{2}$} \\
\hline $\mathrm{n}$ & 687 \\
\hline Mean (SD) & $27.2(8.1)$ \\
\hline Median (Q1, Q3) & $26.5(22.3,31.0)$ \\
\hline \multicolumn{2}{|l|}{ BMI category, n (\%) } \\
\hline $\mathrm{n}$ & 687 \\
\hline Underweight $\left(<18.5 \mathrm{~kg} / \mathrm{m}^{2}\right)$ & $51(7.4)$ \\
\hline Normal $\left(18.5-<25 \mathrm{~kg} / \mathrm{m}^{2}\right)$ & $226(32.9)$ \\
\hline Overweight $\left(25-<30 \mathrm{~kg} / \mathrm{m}^{2}\right)$ & $194(28.2)$ \\
\hline Class I obesity $\left(30-<35 \mathrm{~kg} / \mathrm{m}^{2}\right)$ & $139(20.2)$ \\
\hline Class II obesity $\left(35-<40 \mathrm{~kg} / \mathrm{m}^{2}\right)$ & $44(6.4)$ \\
\hline Class III obesity $\left(\geq 40 \mathrm{~kg} / \mathrm{m}^{2}\right)$ & $33(4.8)$ \\
\hline \multicolumn{2}{|l|}{$\mathrm{HbA} 1 \mathrm{c}, \mathrm{mmol} / \mathrm{mol}$} \\
\hline $\mathrm{n}$ & 357 \\
\hline Mean (SD) & $66.5(25.1)$ \\
\hline \multicolumn{2}{|l|}{ Alcohol use, n (\%) } \\
\hline Never & $177(15.6)$ \\
\hline Former & $136(12.0)$ \\
\hline Current & $582(51.3)$ \\
\hline Unknown & $240(21.1)$ \\
\hline \multicolumn{2}{|l|}{ Smoking status, $\mathrm{n}(\%)$} \\
\hline Never & $324(28.5)$ \\
\hline Former & $453(39.9)$ \\
\hline Current & $214(18.9)$ \\
\hline Unknown & $144(12.7)$ \\
\hline \multicolumn{2}{|c|}{ Duration of CPRD registration before index date, years } \\
\hline Mean (SD) & $9.1(5.8)$ \\
\hline \multicolumn{2}{|c|}{ Duration of follow-up post-index date, years } \\
\hline Mean (SD) & $4.7(3.4)$ \\
\hline \multicolumn{2}{|l|}{ Charlson Comorbidity Index } \\
\hline Mean (SD) & $1.8(2.0)$ \\
\hline Median (Q1, Q3) & $1.0(0.0,3.0)$ \\
\hline \multicolumn{2}{|l|}{ Charlson Comorbidity Index category } \\
\hline 0 & $378(33.3)$ \\
\hline $1-2$ & $439(38.7)$ \\
\hline $3-4$ & $204(18.0)$ \\
\hline$>=5$ & $114(10.0)$ \\
\hline \multicolumn{2}{|l|}{ Comorbidities, n (\%) } \\
\hline Cancer & $109(9.6)$ \\
\hline Cerebrovascular disease & $75(6.6)$ \\
\hline Congestive heart failure & $37(3.3)$ \\
\hline
\end{tabular}




\begin{tabular}{ll}
\hline Table 1 Continued & \\
\hline \multirow{2}{*}{ Study variable } & Patients with gastroparesis \\
\cline { 2 - 2 } & $(\mathbf{n}=1135)$ \\
\hline Chronic pulmonary disease & $309(27.2)$ \\
\hline Dementia & $13(1.1)$ \\
\hline Diabetes with complications & $308(27.1)$ \\
\hline Diabetes & $118(10.4)$ \\
\hline Hemiplegia or paraplegia & $13(1.1)$ \\
\hline HIV/AIDS & $3(0.3)$ \\
\hline Myocardial infarction & $50(4.4)$ \\
\hline Mild liver disease & $21(1.9)$ \\
\hline Moderate or severe liver disease & $6(0.5)$ \\
\hline Metastatic solid tumour & $7(0.6)$ \\
\hline Peptic ulcer disease & $92(8.1)$ \\
\hline Peripheral vascular disease & $60(5.3)$ \\
\hline Renal disease & $147(13.0)$ \\
\hline Rheumatic disease & $69(6.1)$ \\
\hline
\end{tabular}

AIDS, acquired immunodeficiency syndrome; BMI, body mass index; CPRD, Clinical Practice Research Datalink; HbA1c, glycated haemoglobin; HIV, human immunodeficiency virus; SD, standard deviation.

the date of diagnosis was 9.1 years, with an average follow-up duration of 4.7 years. The majority of patients were female $(63.7 \%)$ with a mean age of 50.6 years at the time of diagnosis. Of the 608 patients with ethnicity recorded, the majority were white (85.0\%), 12.2\% were of Indian, Pakistani, Bangladeshi, Chinese or other Asian ethnicity, and 2.8\% were of other ethnicities. With respect to lifestyle factors, $51.3 \%$ of the patients were current consumers of alcohol and, of the patients with a recorded smoking status, $67.3 \%$ of the population were current or former smokers. Completeness of data for BMI in the study population was similar to that of the overall CPRD population. ${ }^{28}$ Of the 687 patients ( $60.5 \%$ of the study population) with gastroparesis with available BMI data, the mean BMI was $27.2 \mathrm{~kg} /$ $\mathrm{m}^{2}$. Only 226 patients $(32.9 \%)$ were of a normal weight and 51 patients (7.4\%) were underweight, whereas the remaining 410 patients $(59.7 \%)$ were overweight or obese. The most frequent aetiology was idiopathic (39.4\%), with diabetic (37.5\%) and drug-induced (19.6\%) gastroparesis being the two next most common aetiologies. All other aetiologies were rare $(<2 \%)$ in the study population (table 2).

\section{Incidence}

The standardised overall incidence of gastroparesis rose from 1.5 (95\% CI 1.1 to 1.8 ) per 100000 person-years in 2004 to 1.9 (95\% CI 1.4 to 2.3) per 100000 person-years in 2016. However, overall incidence of gastroparesis was low, and fluctuated between 1.3 and 2.1 per 100000 person-years during 2004-2016 (figure 2). Similar to observations seen for prevalence, incidence of gastroparesis was higher in women than in men at each time point during 2004-2016. There were too few incident patients each year to allow meaningful analysis for each age category or region, according to year.

\section{Prevalence}

During 2016, the overall period prevalence of gastroparesis was 13.8 (95\% CI 12.6 to 15.1$)$ per 100000 persons in the UK. Subgroup analyses for point prevalence on 1 July 2016 by region, sex and age revealed several interesting findings. Significant regional differences were observed within the UK (figure 3). Scotland had the highest prevalence at 31.7 (95\% CI 27.1 to
Table 2 Aetiology for gastroparesis in the CPRD

\begin{tabular}{|lc}
\hline Aetiology & $\begin{array}{l}\text { Number (\%) of patients with } \\
\text { gastroparesis } \\
(\mathbf{n}=1135)\end{array}$ \\
\hline Idiopathic gastroparesis & $447(39.4 \%)$ \\
\hline Diabetic gastroparesis & $426(37.5 \%)$ \\
\hline Type 1 diabetes & $220(19.4 \%)$ \\
\hline Type 2 diabetes & $162(14.3 \%)$ \\
\hline Type not specified & $44(3.9 \%)$ \\
\hline Drug-induced gastroparesis & \\
\hline At least one drug with potential for delayed & $223(19.6 \%)$ \\
\hline gastric emptying & $152(13.4 \%)$ \\
\hline Opioid analgesics & $57(5.0 \%)$ \\
\hline Calcium-channel blockers & $33(2.9 \%)$ \\
\hline Anticholinergic agents & $13(1.1 \%)$ \\
\hline Postsurgical gastroparesis & $10(0.9 \%)$ \\
\hline Parkinson's disease & $7(0.6 \%)$ \\
\hline Multiple sclerosis & $3(0.3 \%)$ \\
\hline Cerebral palsy & $3(0.3 \%)$ \\
\hline Systemic lupus erythematosus & $3(0.3 \%)$ \\
\hline Scleroderma &
\end{tabular}

CPRD, Clinical Practice Research Datalink.

36.3) per 100000 persons. Several other regions also had a higher prevalence than the national average, including Northern Ireland (23.6 (95\% CI 16.0 to 31.2)), North East England (20.9 (95\% CI 2.6 to 39.2)), East of England (20.0 (95\% CI 11.8 to 28.2)) and North West England (17.9 (95\% CI 11.9 to 23.9)). Other regions demonstrated a lower-than-average prevalence, such as Wales (9.2 (95\% CI 6.7 to 11.7)) and London (with the lowest recorded prevalence at 8.4 (95\% CI 5.2 to 11.6)). Prevalence in women was almost twofold than in men $(20.4)(95 \% \mathrm{CI}$ 17.0 to 23.8 ) vs 10.3 (95\% CI 7.8 to 12.8$)$ ) (table 3). Subgroup analysis also demonstrated that diagnosis of gastroparesis in children (younger than 18 years) was infrequent; paediatric prevalence was only 3.6 (95\% CI 1.2 to 6.0) in the CPRD.

\section{Outcomes}

Following diagnosis, 776 patients $(68.4 \%)$ were prescribed at least one prokinetic (table 4), with the remaining 359 patients (31.6\%) being offered no recognised pharmacological therapy. The most commonly prescribed medications were domperidone in $46.6 \%$ and metoclopramide in $22.9 \%$ of patients. Erythromycin had been prescribed for $6.2 \%$ of patients, while prucalopride and cisapride were prescribed for $<1 \%$ patients.

\section{Diabetic versus idiopathic gastroparesis}

Patients with type 2 diabetic gastroparesis differed from those with type 1 diabetic and idiopathic gastroparesis in several notable factors (table 5). They were older at the time of diagnosis (62.6 years vs 46.3 years in type 1 diabetic and 44.5 years in idiopathic gastroparesis). In addition, a higher proportion of patients with diabetic gastroparesis were overweight or obese than those with idiopathic gastroparesis $(78.1 \%$ of type 2 diabetic and $56.4 \%$ of type 1 diabetic vs $52.3 \%$ of idiopathic gastroparesis). After multivariate Cox regression, patients with idiopathic gastroparesis had a significantly higher survival probability than patients with diabetic gastroparesis, after adjusting for significant predictors in this study population, including age, sex, and presence of cancer, cerebrovascular disease, chronic pulmonary disease, peripheral vascular disease and renal disease. The adjusted HR 


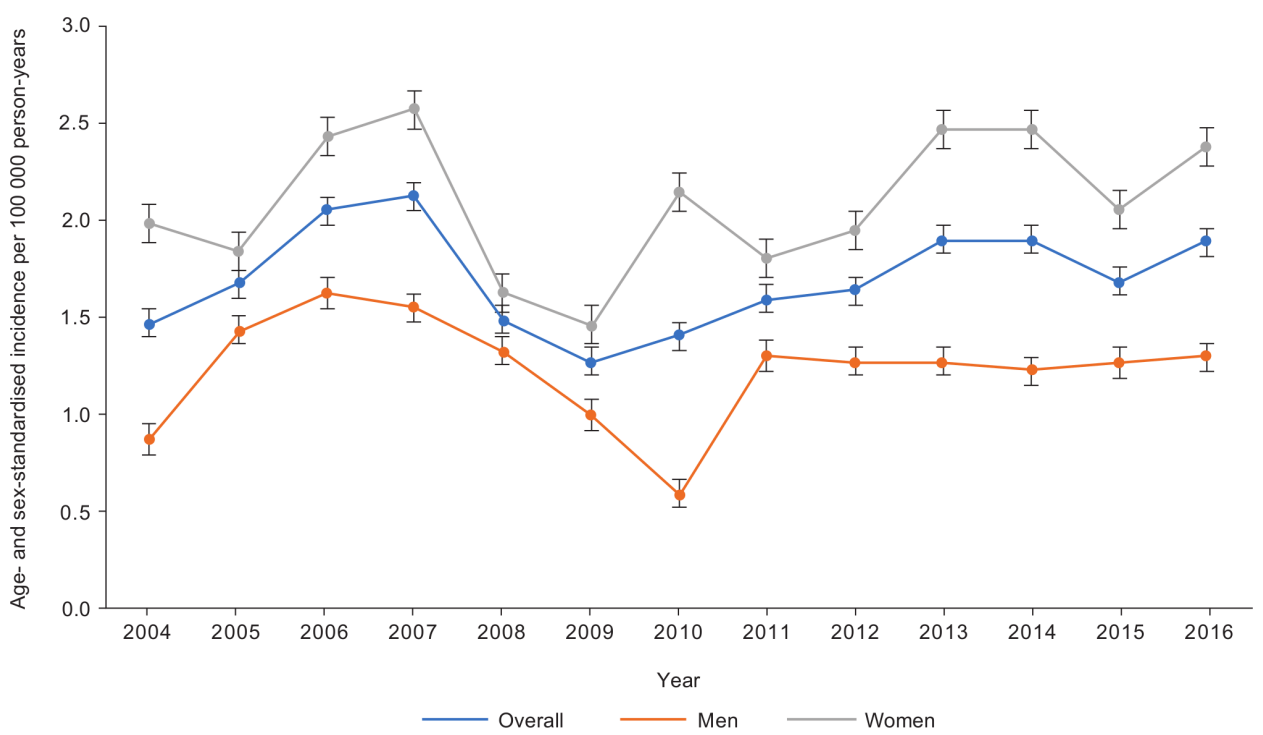

Figure 2 Standardised incidence of gastroparesis in the Clinical Practice Research Datalink, 2004-2016.

for death was 1.9 (95\% CI 1.2 to 3.0 ) in diabetic versus idiopathic gastroparesis (figure 4). Patients with both type 1 diabetic gastroparesis (adjusted HR 2.6, 95\% CI 1.6 to 4.2) and type 2 diabetic gastroparesis (adjusted HR 2.0, 95\% CI 1.2 to 3.4 ) had a significantly higher risk of mortality than patients with idiopathic gastroparesis. However, type of diabetes and general predictors of mortality listed previously were not significantly associated with mortality in patients with diabetic gastroparesis in the CPRD.

\section{DISCUSSION}

To our knowledge, this is the first population-based epidemiological study providing real-world evidence on the prevalence and incidence of gastroparesis in a European country. Our data suggest that the age-standardised and sex-standardised prevalence of documented gastroparesis was 13.8 per 100000 persons in the UK in 2016, and that the standardised incidence ranged from 1.5 to 1.9 per 100000 person-years between 2004 and 2016. Although this estimated prevalence may not seem high, gastroparesis still represents a substantial unmet need in the UK because there are currently no approved treatments, and in our study more than $30 \%$ of patients were not offered any pharmacological therapy following diagnosis.

The previous study in Olmsted County, Minnesota estimated the prevalence of gastroparesis at 24.2 per 100000 persons and the incidence to be 6.3 per 100000 person-years. $^{7}$ These results

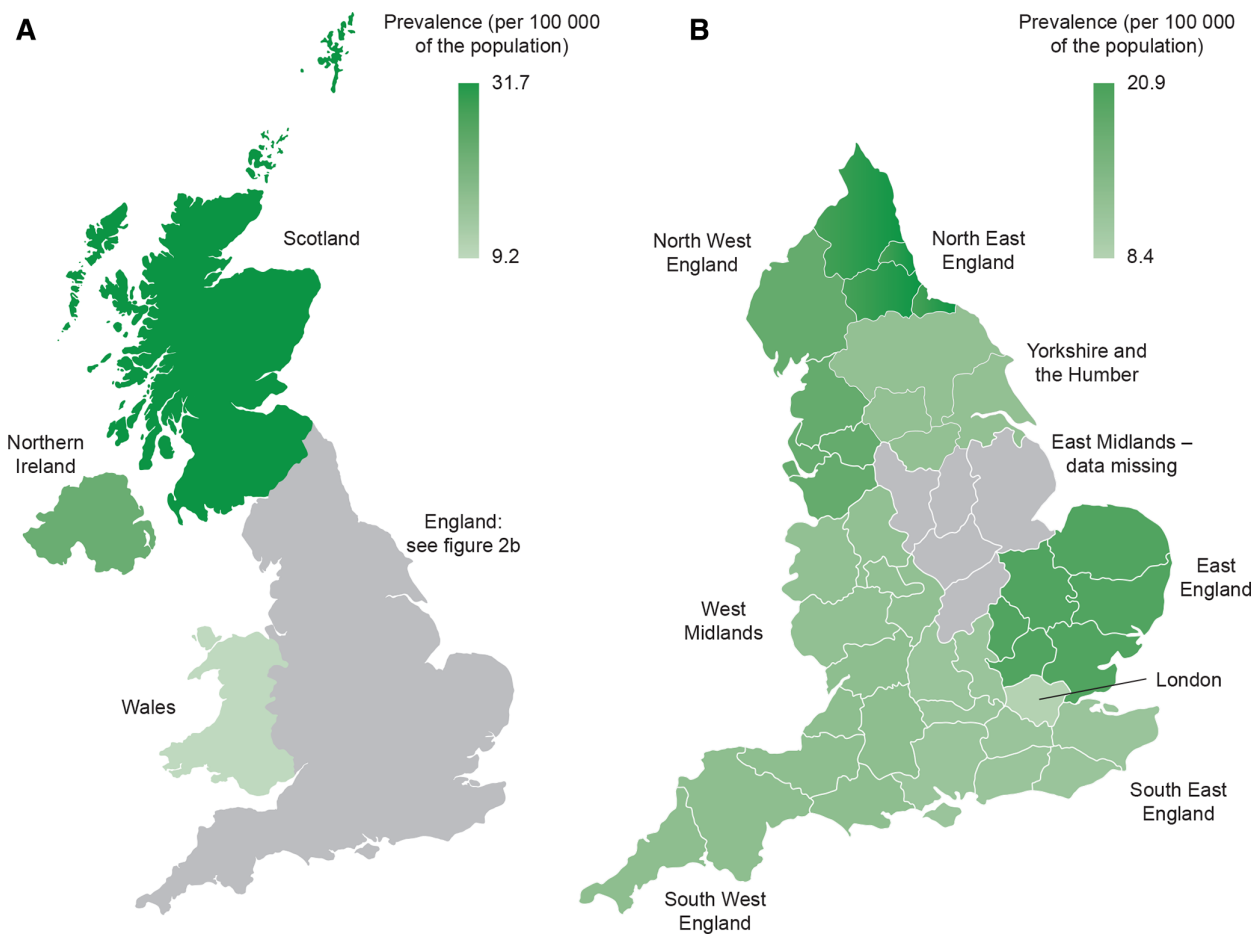

Figure 3 Regional prevalence of gastroparesis in the Clinical Practice Research Datalink (CPRD). (A) Prevalence of gastroparesis by country in the CPRD. (B) Prevalence of gastroparesis by region in England. Prevalence is shown as point prevalence on 1 July 2016. 
Table 3 Subgroup analysis for prevalence of gastroparesis by region, sex and age*

\begin{tabular}{|c|c|c|c|}
\hline Subgroups & $\begin{array}{l}\text { Patients with } \\
\text { gastroparesis }\end{array}$ & $\begin{array}{l}\text { Population in } \\
\text { the CPRD }\end{array}$ & $\begin{array}{l}\text { Standardised } \\
\text { prevalence }(95 \% \mathrm{Cl})\end{array}$ \\
\hline \multicolumn{4}{|l|}{ Region } \\
\hline UK (overall) & 479 & 2926268 & 15.4 (13.3 to 17.5$)$ \\
\hline \multicolumn{4}{|l|}{ England } \\
\hline East of England & 23 & 118333 & 20.0 (11.8 to 28.2$)$ \\
\hline East Midlandst & NA & NA & NA \\
\hline London & 27 & 304711 & $8.4(5.2$ to 11.6$)$ \\
\hline North East & 5 & 24323 & 20.9 (2.6 to 39.2 ) \\
\hline North West & 34 & 192228 & 17.9 (11.9 to 23.9$)$ \\
\hline South East & 71 & 613002 & 11.4 (8.8 to 14.1$)$ \\
\hline South West & 22 & 175789 & 13.0 (7.5 to 18.5$)$ \\
\hline West Midlands & 24 & 188643 & 12.4 (7.4 to 17.4$)$ \\
\hline Yorkshire and the Humber & 3 & 21963 & 12.5 (0.0 to 26.6$)$ \\
\hline Scotland & 180 & 570821 & 31.7 (27.1 to 36.3$)$ \\
\hline Northern Ireland & 37 & 148300 & 23.6 (16.0 to 31.2) \\
\hline Wales & 53 & 568155 & $9.2(6.7$ to 11.7$)$ \\
\hline \multicolumn{4}{|l|}{ Sex } \\
\hline Male & 170 & 1447569 & 10.3 (7.8 to 12.8$)$ \\
\hline Female & 309 & 1478699 & 20.4 (17.0 to 23.8$)$ \\
\hline \multicolumn{4}{|l|}{ Age group in years } \\
\hline $0-17$ & 14 & 595958 & $3.6(1.2$ to 6.0$)$ \\
\hline $18-29$ & 41 & 414863 & $8.2(5.1$ to 11.3$)$ \\
\hline $30-39$ & 58 & 392033 & 11.8 (7.6 to 15.9$)$ \\
\hline $40-49$ & 78 & 411954 & 18.4 (11.2 to 25.5$)$ \\
\hline $50-59$ & 93 & 407911 & 22.4 (14.9 to 29.9$)$ \\
\hline $60-69$ & 85 & 322436 & 28.3 (18.4 to 38.3 ) \\
\hline $70-79$ & 61 & 229605 & 23.7 (16.5 to 31.0$)$ \\
\hline $80+$ & 49 & 151508 & 30.7 (18.8 to 42.6$)$ \\
\hline
\end{tabular}

* Subgroup analysis used point prevalence on 1 July 2016

†General practices in East Midlands did not contribute to the CPRD in 2016.

CPRD, Clinical Practice Research Datalink; NA, not applicable.

lack generalisability to the UK general population because they were collected in an ethnically homogeneous local population; the study population was greater than $90 \%$ White, ${ }^{29}$ as opposed to $85 \%$ White, $12.2 \%$ of Indian, Pakistani, Bangladeshi, Chinese or other Asian ethnicity, and 2.8\% another ethnicity in our representative nationwide sample from the CPRD. ${ }^{30}$ Another US study that examined a national EHR database reported that $0.16 \%$ of charts (not patients) had a diagnosis of gastroparesis recorded. ${ }^{31}$ However, the result was not standardised by demographic variables, such as age and sex, in order to estimate a populationbased disease prevalence. The applicability of these findings to other countries and populations is therefore questionable.

We found that the majority of patients with gastroparesis in the CPRD were overweight or obese. Contrary to previous

Table 4 Pharmacological therapies for gastroparesis in the CPRD

\begin{tabular}{ll}
\hline Treatment for gastroparesis & $\begin{array}{l}\text { Number }(\%) \text { of patients } \\
\text { with gastroparesis } \\
(\mathbf{n}=1135)\end{array}$ \\
\hline Received at least one treatment for gastroparesis & $776(68.4 \%)$ \\
\hline Domperidone & $529(46.6 \%)$ \\
\hline Metoclopramide & $260(22.9 \%)$ \\
\hline Erythromycin & $70(6.2 \%)$ \\
\hline Prucalopride & $7(0.6 \%)$ \\
\hline Cisapride & $5(0.4 \%)$ \\
\hline
\end{tabular}

CPRD, Clinical Practice Research Datalink.
Table 5 Demographic characteristics of patients with type 1 diabetic, type 2 diabetic and idiopathic gastroparesis in the CPRD

\begin{tabular}{|c|c|c|c|}
\hline \multirow{2}{*}{ Study variable } & Type 1 diabetes & Type 2 diabetes & Idiopathic \\
\hline & $(n=220)$ & $(n=162)$ & $(n=447)$ \\
\hline \multicolumn{4}{|l|}{ Sex, n (\%) } \\
\hline Female & $133(60.5)$ & $111(68.5)$ & $273(61.1)$ \\
\hline Male & $87(39.5)$ & $51(31.5)$ & $174(38.9)$ \\
\hline \multicolumn{4}{|c|}{ Age at first gastroparesis diagnosis, years } \\
\hline Mean (SD) & $46.3(16.1)$ & $62.6(12.2)$ & $44.5(21.7)$ \\
\hline \multicolumn{4}{|l|}{ Ethnicity, $\mathrm{n}(\%)$} \\
\hline $\mathrm{n}$ & 119 & 97 & 230 \\
\hline White & $108(90.8)$ & $73(75.3)$ & $191(83.0)$ \\
\hline Asian & $11(9.2)$ & $17(17.5)$ & $35(15.2)$ \\
\hline Other & $0(0.0)$ & $7(7.2)$ & $4(1.7)$ \\
\hline \multicolumn{4}{|l|}{ Body weight, $\mathrm{kg}$} \\
\hline $\mathrm{n}$ & 181 & 150 & 214 \\
\hline Mean (SD), kg & $75.4(20.4)$ & $82.2(21.3)$ & $69.2(20.4)$ \\
\hline \multicolumn{4}{|l|}{$\mathrm{BMI}, \mathrm{kg} / \mathrm{m}^{2}$} \\
\hline $\mathrm{n}$ & 179 & 150 & 199 \\
\hline Mean (SD) & $26.4(6.5)$ & $30.2(7.0)$ & $26.3(10.6)$ \\
\hline Median (Q1, Q3) & $25.4(22.2,30.4)$ & $30.4(25.5,33.5)$ & $25.3(21.1,29.3)$ \\
\hline
\end{tabular}

\begin{tabular}{lccc}
$\mathrm{n}$ & 179 & 150 & 199 \\
Underweight $\left(<18.5 \mathrm{~kg} / \mathrm{m}^{2}\right)$ & $14(7.8)$ & $4(2.7)$ & $20(10.1)$ \\
\hline Normal $\left(18.5-<25 \mathrm{~kg} / \mathrm{m}^{2}\right)$ & $64(35.8)$ & $29(19.3)$ & $75(37.7)$ \\
Overweight $\left(25-<30 \mathrm{~kg} / \mathrm{m}^{2}\right)$ & $50(27.9)$ & $37(24.7)$ & $62(31.2)$ \\
Class I obesity $\left(30-<35 \mathrm{~kg} / \mathrm{m}^{2}\right)$ & $36(20.1)$ & $51(34.0)$ & $27(13.6)$ \\
Class II obesity $\left(35-<40 \mathrm{~kg} / \mathrm{m}^{2}\right)$ & $7(3.9)$ & $16(10.7)$ & $10(5.0)$ \\
Class III obesity $\left(\geq 40 \mathrm{~kg} / \mathrm{m}^{2}\right)$ & $8(4.5)$ & $13(8.7)$ & $5(2.5)$ \\
HbA1c, mmol $/ \mathrm{mol}$ & & &
\end{tabular}

$\mathrm{HbA1c}, \mathrm{mmol} / \mathrm{mol}$

\begin{tabular}{|c|c|c|c|}
\hline $\mathrm{n}$ & 185 & 145 & 11 \\
\hline Mean (SD) & $72.9(25.8)$ & $63.3(21.8)$ & $36.7(4.7)$ \\
\hline \multicolumn{4}{|l|}{ Alcohol use, $n(\%)$} \\
\hline Never & $30(13.6)$ & $36(22.2)$ & $61(13.6)$ \\
\hline Former & $46(20.9)$ & $35(21.6)$ & $23(5.1)$ \\
\hline Current & $115(52.3)$ & $65(40.1)$ & $236(52.8)$ \\
\hline Unknown & $29(13.2)$ & $26(16.0)$ & $127(28.4)$ \\
\hline \multicolumn{4}{|l|}{ Smoking status, $\mathrm{n}(\%)$} \\
\hline Never & $44(20.0)$ & $31(19.1)$ & $165(36.9)$ \\
\hline Former & $92(41.8)$ & $91(56.2)$ & $153(34.2)$ \\
\hline Current & $57(25.9)$ & $24(14.8)$ & $66(14.8)$ \\
\hline Unknown & $27(12.3)$ & $16(9.9)$ & $63(14.1)$ \\
\hline \multicolumn{4}{|c|}{ Duration of registration before index date, years } \\
\hline Mean (SD) & $8.9(6.0)$ & $10.7(6.0)$ & $8.4(5.7)$ \\
\hline \multicolumn{4}{|c|}{ Duration of follow-up post-index date, years } \\
\hline Mean (SD) & $4.3(3.2)$ & $3.9(2.7)$ & $5.2(3.5)$ \\
\hline \multicolumn{4}{|c|}{ Charlson Comorbidity Index } \\
\hline Mean (SD) & $3.4(1.9)$ & $3.4(2.0)$ & $0.7(1.2)$ \\
\hline Median (01, 03) & $3.0(2.0,4.0)$ & $3.0(2.0,5.0)$ & $0.0(0.0 .1$ \\
\hline
\end{tabular}

Charlson Comorbidity Index category,

$\mathrm{n}(\%)$

\begin{tabular}{lccr}
\hline & $0(0.0)$ & $0(0.0)$ & $266(59.5)$ \\
$1-2$ & $93(42.3)$ & $66(40.7)$ & $149(33.3)$ \\
$3-4$ & $78(35.5)$ & $54(33.3)$ & $27(6.0)$ \\
$>=5$ & $49(22.3)$ & $42(25.9)$ & $5(1.1)$ \\
Comorbidities, n(\%) & & & \\
Cancer & $12(5.5)$ & $25(15.4)$ & $40(8.9)$ \\
Cerebrovascular disease & $28(12.7)$ & $16(9.9)$ & $11(2.5)$ \\
Congestive heart failure & $12(5.5)$ & $11(6.8)$ & $6(1.3)$ \\
Chronic pulmonary disease & $60(27.3)$ & $53(32.7)$ & $95(21.3)$ \\
Dementia & $2(0.9)$ & $4(2.5)$ & $0(0.0)$ \\
Diabetes with complications & $206(93.6)$ & $102(63.0)$ & $0(0.0)$ \\
Diabetes & $14(6.4)$ & $60(37.0)$ & $0(0.0)$ \\
Hemiplegia or paraplegia & $1(0.5)$ & $2(1.2)$ & $2(0.4)$ \\
HIV/AlDS & $0(0.0)$ & $1(0.6)$ & $0(0.0)$ \\
Myocardial infarction & $16(7.3)$ & $8(4.9)$ & $14(3.1)$ \\
\hline
\end{tabular}

Continued 


\begin{tabular}{|c|c|c|c|}
\hline \multirow{2}{*}{ Study variable } & Type 1 diabetes & Type 2 diabetes & Idiopathic \\
\hline & $(n=220)$ & $(n=162)$ & $(n=447)$ \\
\hline Mild liver disease & $6(2.7)$ & $6(3.7)$ & $5(1.1)$ \\
\hline Moderate or severe liver disease & $3(1.4)$ & $1(0.6)$ & $0(0.0)$ \\
\hline Metastatic solid tumour & $0(0.0)$ & $1(0.6)$ & $3(0.7)$ \\
\hline Peptic ulcer disease & $14(6.4)$ & $13(8.0)$ & $30(6.7)$ \\
\hline Peripheral vascular disease & $28(12.7)$ & $16(9.9)$ & $6(1.3)$ \\
\hline Renal disease & $58(26.4)$ & $43(26.5)$ & $18(4.0)$ \\
\hline Rheumatic disease & $15(6.8)$ & $12(7.4)$ & $14(3.1)$ \\
\hline
\end{tabular}

AIDS, acquired immunodeficiency syndrome; BMI, body mass index; CPRD, Clinical Practice Research Datalink; HbA1C, glycated haemoglobin; HIV, human immunodeficiency virus; SD, standard deviation.

beliefs, ${ }^{32}$ this evidence from a real-world setting suggests that the chronic nausea and vomiting associated with gastroparesis may not always lead to weight loss. The coexistence of obesity should, therefore, not preclude consideration of gastroparesis as a potential cause of upper GI symptoms, especially in patients with type 2 diabetes. To put these results in context, mean BMI among patients with gastroparesis in the Olmsted County study was $24.9 \pm 6.8$ versus $27.2 \pm 8.1$ in the CPRD. ${ }^{7}$ A higher proportion of patients with type 2 diabetic gastroparesis in the CPRD were overweight or obese than those with type 1 diabetic gastroparesis or idiopathic gastroparesis. Given the association of obesity with an increased risk of developing insulin resistance and type 2 diabetes mellitus, ${ }^{33}$ this is perhaps not surprising. However, our observation that approximately $50 \%$ of patients with idiopathic gastroparesis were also overweight or obese supports data reported by the NIH consortium in the USA. ${ }^{17} 34$ On further investigation, Parkman et al concluded that patients with idiopathic gastroparesis consume and expend less calories than healthy controls, and postulated that weight gain could be possible in the presence of less severe symptoms. ${ }^{35}$ Without information on the severity of symptoms, we are unable to address this hypothesis in CPRD and further research is required.

Other than underlying patient factors, the structure of the UK healthcare system may partially contribute to the differences in results between our study and previous published literature. Given that the symptom pattern of gastroparesis and functional dyspepsia overlap closely, it can be very difficult to distinguish between these two conditions on clinical grounds without gastric emptying tests. Over $80 \%$ of patients with gastroparesis met criteria for functional dyspepsia in one study. ${ }^{17}$ Gastroenterologists may not refer patients for a gastric emptying study in the absence of more concerning symptoms that raise suspicion of a diagnosis of gastroparesis, such as vomiting or weight loss. Also of relevance is the fact that symptom management will be the same regardless of the gastric emptying study results, except in severe cases in which invasive treatments, such as gastroelectrical stimulation or botulinum toxin injection, ${ }^{36-38}$ may be required. In addition, the most widely used prokinetic agents in the UK, domperidone and metoclopramide, are restricted to short-term use only, owing to safety concerns regarding cardiac arrhythmias and extrapyramidal symptoms. ${ }^{39-41}$

There are also the financial pressures experienced by the National Health Service, which are reflected in healthcare policy, which may affect the willingness of GPs to refer patient groups with symptoms considered to be less severe, owing to the associated costs. In the case of gastroparesis, and the overlap of symptoms with functional dyspepsia, this is illustrated by the National Institute for Health and Care Excellence guideline for the management of dyspepsia, ${ }^{18} 19$ which since 2004 has discouraged early referral for endoscopy in patients with presumed dyspepsia without alarming symptoms. Instead, this guideline recommends that these patients are managed in primary care, with either empirical proton pump inhibitor therapy or testing for, and treatment of, Helicobacter pylori ${ }^{18}$ Implementation of this guidance may have reduced the number of patients with presumed functional dyspepsia, who actually have gastroparesis, reaching secondary care. These changes to healthcare policy over the past 15 years, which coincide with the timeframe of this study, could also have altered the recorded incidence and prevalence of gastroparesis in the UK, and the true incidence and prevalence may actually be higher than we report.

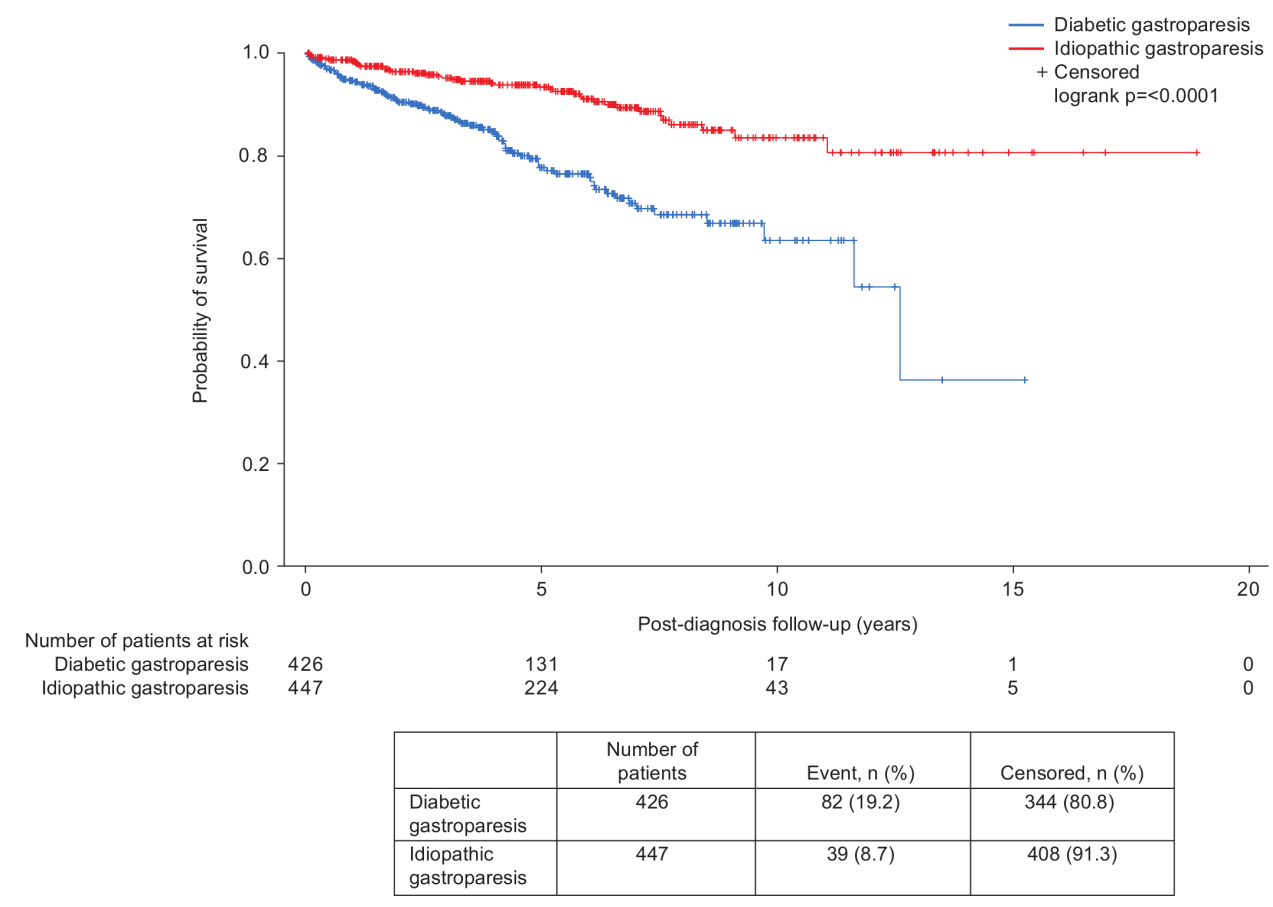

Figure 4 Survival of patients with diabetic and idiopathic gastroparesis in the Clinical Practice Research Datalink. 
Our subgroup analysis showed statistically significant variability among countries and regions of the UK. Scotland had the highest prevalence of all areas studied at 31.7 per 100000 persons, almost four times the lowest recorded prevalence, which was seen in London. Variation in modifiable risk factors for gastroparesis, as well as social and environmental factors, between Scottish and Northern Irish populations and the rest of the UK has previously been noted, and Scotland and Northern Ireland have been found to have higher rates of cancer, cardiovascular disease and obesity than the rest of the UK. ${ }^{42-44}$ The general population of Scotland also has a higher mortality, which cannot be fully explained by sociodemographic or behavioural factors. ${ }^{43}$ When considering our results in this context, the higher prevalence of gastroparesis in Scotland and Northern Ireland may, in part, result from lifestyle factors, but may be further affected by socioeconomic influences within these populations. Another potential contributor to the regional differences we observed may be region-specific variation in education and training received regarding the investigation and management of upper GI symptoms, meaning that GPs in one region are more likely to make a diagnosis of functional dyspepsia, and others in another area gastroparesis. As previously reported in the literature, gastroparesis was seen to predominate in women compared with men in this study. Female predominance was seen in every region studied, with an almost 2:1 ratio in the UK as a whole, although this is less than the $4: 1$ ratio previously reported in Olmsted County. ${ }^{7}$

There has been no consensus on predominant aetiology, but idiopathic and diabetic gastroparesis are considered to be the most common causes. ${ }^{11} 1246$ In our study population, approximately $40 \%$ of patients were deemed to have idiopathic gastroparesis, and a similar proportion of patients had a diabetic aetiology. In the previous study in Olmsted County, 49\% of patients were deemed to have idiopathic gastroparesis versus $25 \%$ of patients who were recorded as having diabetic gastroparesis. ${ }^{7}$ This discrepancy in recorded disease aetiologies for patients with gastroparesis between the UK and the USA has been noted previously, ${ }^{47}$ and again suggests substantial differences in the investigation of upper GI symptoms, disease awareness, and labelling of the condition between the UK and the USA. Among the 223 patients who were judged as having drug-induced gastroparesis, the third most common cause in CPRD, 152 (amounting to $13 \%$ of the entire study population) were using opioid analgesic. Indications for prescriptions are not available in the CPRD database, so we are unable to unpick whether opioids were prescribed for abdominal pain, which is a symptom of gastroparesis, or whether their use predated the diagnosis. Certainly, abdominal pain as a recorded complaint was not common; only 14\% had documented abdominal pain within the 3 months prior to opioid initiation.

To our knowledge, this is the first population-based epidemiological study to investigate the prevalence and incidence of gastroparesis in Europe. The database encompassed 4.4 million active patients who met CPRD's quality criteria for research, providing a large representative sample of the UK population with substantial follow-up time. Misclassification between incident and prevalent cases, due to lack of observable person-time, was minimised by a sufficient baseline period of 9.1 years and a follow-up time of 4.7 years, on average, for censoring. Extensive statistical analyses were conducted to ensure our results were robust and to understand the context of the findings. Both period prevalence and point prevalence were used to estimate prevalence and generated similar results, confirming that both measurements are reliable. Subgroup analysis by sex confirmed a female predominance, which has been observed in previous studies, although our study population had a higher percentage of male patients. Subgroup analyses demonstrated as large as a fourfold difference in prevalence across different areas of the UK, suggesting that the likelihood of a diagnosis of gastroparesis being made may differ considerably according to geography, and that prevalence increased steadily with age. The condition was rarely diagnosed among children, and prevalence was highest in those who were 60-69 years of age in the UK. Finally, this study has described the treatment, survival and aetiology of patients with gastroparesis in the UK. CPRD with linkage to HES-ONS death registry data has been shown previously to be sufficient for censoring follow-up and calculating mortality. ${ }^{48}$ We demonstrate that patients with diabetic gastroparesis had an almost twofold mortality to those with idiopathic gastroparesis, after adjusting for significant predictors.

This study has several limitations that require consideration. As the CPRD is a primary care EHR database, specialist documents, such as requests for tests in, and letters from, secondary care, are scanned into primary care records and may, therefore, not be indexed by the GP practice into the database. In addition, handling of these documents and the associated coding may differ among GPs, and accuracy of assigning the correct medical or Read codes varies. ${ }^{49} 50$ The necessary investigations to confirm a diagnosis of gastroparesis, such as gastric emptying studies, are only available in secondary or tertiary care. This means that a failure to record the results of these tests in GP records, or discrepancies in management of documentation or coding, could lead to misclassification of patients in this primary care database. The present data are, therefore, only representative of patients with a diagnosis of gastroparesis recorded according to the study inclusion criteria. It may be difficult for patients to obtain a clinical diagnosis of gastroparesis and, as has already been discussed, it is possible that some patients with genuine gastroparesis may have been misdiagnosed with other conditions, such as functional dyspepsia, or were unable to acquire a referral for confirmatory diagnostic testing. Such misclassification would tend to underestimate both the prevalence and incidence of gastroparesis in our study, and suggests that any patients identified by the definition we used are unlikely to be free of gastroparesis. As a result, the true prevalence and incidence of gastroparesis are likely to be higher than our estimates. In addition, although standardised by age and sex, our study results are derived from a primary care population in the UK and may not, therefore, be directly compared with other populations and healthcare systems. Nevertheless, CPRD patients are broadly representative of the UK general population in terms of age, sex, ethnicity and BMI. $^{23}$ Therefore, we believe that our findings are still likely to be representative of patients with gastroparesis diagnosed in the UK. We observed that the adjusted overall survival in patients with diabetic gastroparesis was significantly lower than that of patients with idiopathic gastroparesis. Although several known risk factors for death, including BMI, and tobacco and alcohol intake, were not significant predictors of death in the study population, we were unable to control for other potential contributors for death including severity of gastroparesis and specific diabetic complications in this database. In addition, despite the introduction of the Quality Outcomes Framework incentives for diabetes coding in 2004, type of diabetes was unavailable for $10 \%$ of patients with presumed diabetic gastroparesis. We recognise that another important limitation is that there is no information on symptom patterns among patients with gastroparesis. Our original study proposal had examination of this issue as an a priori objective. However, subsequent dataset exploration uncovered that many of the symptoms of interest could not be accurately identified due to the lack of a proper Read code or a validated algorithm. 
In conclusion, this study provides a critical addition to the sparse epidemiological data concerning gastroparesis in the literature. Despite limitations, this is the first population-based study to generate real-world evidence on the incidence and prevalence of gastroparesis in a European country. The study findings advance our knowledge related to patient characteristics, management and aetiology of gastroparesis in the UK. There is also a need for further research to understand fully the factors that may affect outcomes and survival of patients with gastroparesis.

\section{Author affiliations}

Global Evidence and Outcomes, Takeda Pharmaceutical Company Ltd, Cambridge, Massachusetts, USA

${ }^{2}$ Safety and Observational Statistics, Takeda Pharmaceutical Company Ltd, Cambridge, Massachusetts, USA

${ }^{3}$ Clinical Science, Takeda Pharmaceutical Company Ltd, Cambridge, Massachusetts, USA

${ }^{4}$ Perelman School of Medicine, Adjunct, University of Pennsylvania, Philadelphia, Pennsylvania, USA

${ }^{5}$ Global Evidence and Outcomes, Takeda Development Centre Europe, London, UK ${ }^{6}$ Leeds Institute of Medical Research at St. James's, University of Leeds, Leeds, UK 7Leeds Gastroenterology Institute, Leeds Teaching Hospitals NHS Trust, Leeds, UK

Contributors YY designed the study, wrote the statistical analysis plan, reviewed and interpreted study results, and drafted and revised the paper. BJ wrote the statistical analysis plan and cleaned, analysed the data and revised the paper. SM wrote the statistical analysis plan, cleaned and analysed the data, and revised the paper. PLM reviewed and interpreted study results and revised the paper. CA reviewed and interpreted study results, and revised the paper. DB designed the study, reviewed and interpreted study results, and revised the paper. PD designed the study, reviewed and interpreted study results, and revised the paper. ACF reviewed and interpreted study results, and drafted and critically revised the paper. ACF and PD jointly hold the position of last-place author.

Funding This study was sponsored by Takeda Pharmaceutical Company Ltd. Editorial support was provided by Oxford PharmaGenesis Ltd and was supported by Takeda Pharmaceutical Company Ltd.

Competing interests YY, BJ, SM, PLM, CA, DB and PD are employees of Takeda Pharmaceutical Company Ltd. and receive stock or stock options at the time of study. ACF has previously received speakers' fees from Takeda Pharmaceutical Company Ltd.

Patient and public involvement Patients and/or the public were not involved in the design, or conduct, or reporting, or dissemination plans of this research.

Patient consent for publication Not required.

Ethics approval This study was approved by the Independent Scientific Advisory Committee for CPRD research in June 2018 (protocol: 18 110RA).

Provenance and peer review Not commissioned; externally peer reviewed.

Data availability statement Data may be obtained from a third party and are not publicly available. Deidentified study data were obtained via an encrypted and password-protected website provided by the CPRD per ISAC approval (approval ID: 18_110RA).

Open access This is an open access article distributed in accordance with the Creative Commons Attribution Non Commercial (CC BY-NC 4.0) license, which permits others to distribute, remix, adapt, build upon this work non-commercially, and license their derivative works on different terms, provided the original work is properly cited, appropriate credit is given, any changes made indicated, and the use is non-commercial. See: http://creativecommons.org/licenses/by-nc/4.0/.

\section{ORCID iD}

Yizhou Ye http://orcid.org/0000-0002-9090-9431

\section{REFERENCES}

1 Masaoka T, Tack J. Gastroparesis: current concepts and management. Gut Liver 2009:3:166-73

2 Camilleri M, Chedid V, Ford AC, et al. Gastroparesis. Nat Rev Dis Primers 2018;4:41.

3 Shafi MA, Pasricha PJ. Post-surgical and obstructive gastroparesis. Curr Gastroenterol Rep 2007;9:280-5.

4 Camilleri M, Parkman HP, Shafi MA, et al. Clinical guideline: management of gastroparesis. Am J Gastroenterol 2013;108:18-37.

5 Parkman HP, Hasler WL, Fisher RS, et al. American Gastroenterological Association technical review on the diagnosis and treatment of gastroparesis. Gastroenterology 2004; 127:1592-622.
6 Hasler WL, Parkman HP, Wilson LA, et al. Psychological dysfunction is associated with symptom severity but not disease etiology or degree of gastric retention in patients with gastroparesis. Am J Gastroenterol 2010;105:2357-67.

7 Jung H-K, Choung RS, Locke GR, Schleck C, et al. The incidence, prevalence, and outcomes of patients with gastroparesis in Olmsted County, Minnesota, from 1996 to 2006. Gastroenterology 2009;136:1225-33.

8 Wadhwa V, Mehta D, Jobanputra Y, et al. Healthcare utilization and costs associated with gastroparesis. World J Gastroentero/ 2017;23:4428-36.

9 Yu D, Ramsey FV, Norton WF, et al. The burdens, concerns, and quality of life of patients with gastroparesis. Dig Dis Sci 2017;62:879-93.

10 Navas CM, Crowell MD, Lacy BE. The willingness of patients with gastroparesis to take risks with medications. Aliment Pharmacol Ther 2019;49:429-36.

11 Bharucha AE. Epidemiology and natural history of gastroparesis. Gastroenterol Clin North Am 2015;44:9-19.

12 Soykan I, Sivri B, Sarosiek I, et al. Demography, clinical characteristics, psychological and abuse profiles, treatment, and long-term follow-up of patients with gastroparesis. Dig Dis Sci 1998;43:2398-404

13 Wang YR, Fisher RS, Parkman HP. Gastroparesis-related hospitalizations in the United States: trends, characteristics, and outcomes, 1995-2004. Am J Gastroenterol 2008; 103:313-22

14 Jones KL, Russo A, Stevens JE, et al. Predictors of delayed gastric emptying in diabetes. Diabetes Care 2001:24:1264-9.

15 Hasler WL. Geography lessons: scrutinizing state-by-state differences in inpatient gastroparesis care. Dig Dis Sci 2013:58:2743-5.

16 St Sauver JL, Grossardt BR, Leibson CL, et al. Generalizability of epidemiological findings and public health decisions: an illustration from the Rochester Epidemiology Project. Mayo Clin Proc 2012;87:151-60.

17 Parkman HP, Yates K, Hasler WL, et al. Clinical features of idiopathic gastroparesis vary with sex, body mass, symptom onset, delay in gastric emptying, and gastroparesis severity. Gastroenterology 2011;140:101-15.

18 National Institute of Health and Care Excellence. Gastro-oesophageal reflux disease and dyspepsia in adults: investigation and management (Clinical guideline [CG184]), 2014. Available: https://www.nice.org.uk/guidance/cg184

19 National Institute of Health and Care Excellence. Dyspepsia: managing dyspepsia in adults in primary care (Clinical guideline [CG17]), 2004. Available: www.nice.org.uk/ nicemedia/pdf/CG017fullguideline.pd

20 Whicher CA, O'Neill S, Holt RIG. Diabetes in the UK: 2019. Diabet Med 2020;37:242-7.

21 Bullard KM, Cowie CC, Lessem SE, et al. Prevalence of diagnosed diabetes in adults by diabetes type-United States, 2016. MMWR Morb Mortal Wkly Rep 2018:67:359-61.

22 Medicines and Healthcare products Regulatory Agency. Clinical practice research Datalink. Available: https://www.cprd.com

23 Herrett E, Gallagher AM, Bhaskaran K, et al. Data resource profile: Clinical Practice Research Datalink (CPRD). Int J Epidemiol 2015;44:827-36.

24 National Health Service. Hospital admitted patient care activity, 2017-18. Available: https://digital.nhs.uk/data-and-information/publications/statistical/hospital-admittedpatient-care-activity/2017-18

25 Office for National Statistics. Deaths. Available: https://www.ons.gov.uk/peoplepopula tionandcommunity/birthsdeathsandmarriages/deaths

26 Lewis JD, Bilker WB, Weinstein RB, et al. The relationship between time since registration and measured incidence rates in the General Practice Research Database. Pharmacoepidemiol Drug Saf 2005;14:443-51.

27 Tate AR, Dungey S, Glew S, et al. Quality of recording of diabetes in the UK: how does the GP's method of coding clinical data affect incidence estimates? Cross-sectional study using the CPRD database. BMJ Open 2017;7:e012905

28 Bhaskaran K, Forbes HJ, Douglas I, et al. Representativeness and optimal use of body mass index (BMI) in the UK Clinical Practice Research Datalink (CPRD). BMJ Open 2013:3:e003389.

29 Wi C-I, St Sauver JL, Jacobson DJ, et al. Ethnicity, socioeconomic status, and health disparities in a mixed rural-urban US Community_-Olmsted County, Minnesota. Mayo Clin Proc 2016;91:612-22.

30 Mathur R, Bhaskaran K, Chaturvedi N, et al. Completeness and usability of ethnicity data in UK-based primary care and hospital databases. J Public Health 2014;36:684-92

31 Syed AR, Wolfe MM, Calles-Escandon J. Epidemiology and diagnosis of gastroparesis in the United States: a population-based study. J Clin Gastroenterol 2020:54:50-4

32 Kashyap P, Farrugia G. Diabetic gastroparesis: what we have learned and had to unlearn in the past 5 years. Gut 2010:59:1716-26.

33 Kahn SE, Hull RL, Utzschneider KM. Mechanisms linking obesity to insulin resistance and type 2 diabetes. Nature 2006:444:840-6.

34 Parkman HP, Yates K, Hasler WL, et al. Similarities and differences between diabetic and idiopathic gastroparesis. Clin Gastroenterol Hepatol 2011;9:quiz e1334:1056-64.

35 Homko CJ, Zamora LC, Boden G, et al. Bodyweight in patients with idiopathic gastroparesis: roles of symptoms, caloric intake, physical activity, and body metabolism. Neurogastroenterol Motil 2014;26:283-9. 
36 National Institute of Health and Care Excellence. Gastroelectrical stimulation for gastroparesis (Interventional procedures guidance [IPG489]), 2014. Available: https:// www.nice.org.uk/guidance/IPG489

37 Ukleja A, Tandon K, Shah K, et al. Endoscopic botox injections in therapy of refractory gastroparesis. World J Gastrointest Endosc 2015;7:790-8.

38 Lacy BE, Crowell MD, Schettler-Duncan A, et al. The treatment of diabetic gastroparesis with botulinum toxin injection of the pylorus. Diabetes Care 2004;27:2341-7.

39 Medicines and Healthcare products Regulatory Agency. Domperidone: risks of cardiac side effects, 2014. Available: https://www.gov.uk/drug-safety-update/domperidonerisks-of-cardiac-side-effects

40 European Medicines Agency. European Medicines Agency recommends changes to the use of metoclopramide, 2014. Available: https://www.ema.europa.eu/en/ medicines/human/referrals/metoclopramide-containing-medicines

41 Medicines and Healthcare products Regulatory Agency. Metoclopramide: risk of neurological adverse effects, 2014. Available: https://www.gov.uk/drug-safety-update/ metoclopramide-risk-of-neurological-adverse-effects

42 Brown KF, Rumgay H, Dunlop C, et al. The fraction of cancer attributable to modifiable risk factors in England, Wales, Scotland, Northern Ireland, and the United Kingdom in 2015. Br J Cancer 2018;118:1130-41.

43 Shelton NJ. Regional risk factors for health inequalities in Scotland and England and the "Scottish effect". Soc Sci Med 2009;69:761-7.
44 Scarborough P, Morgan RD, Webster P, et al. Differences in coronary heart disease, stroke and cancer mortality rates between England, Wales, Scotland and Northern Ireland: the role of diet and nutrition. BMJ Open 2011;1:e000263.

45 McCartney G, Russ TC, Walsh D, et al. Explaining the excess mortality in Scotland compared with England: pooling of 18 cohort studies. J Epidemiol Community Health 2015;69:20-7.

46 Bityutskiy LP, Soykan I, McCallum RW. Viral gastroparesis: a subgroup of idiopathic gastroparesis_clinical characteristics and long-term outcomes. Am J Gastroenterol 1997;92:1501-4.

47 Burlen J, Runnels M, Mehta M, et al. Efficacy of gastric electrical stimulation for gastroparesis: US/European comparison. Gastroenterology Res 2018;11:349-54.

48 Gallagher AM, Dedman D, Padmanabhan S, et al. The accuracy of date of death recording in the Clinical Practice Research Datalink GOLD database in England compared with the Office for National Statistics death registrations. Pharmacoepidemiol Drug Saf 2019;28:563-9.

49 Khan NF, Harrison SE, Rose PW. Validity of diagnostic coding within the General Practice Research Database: a systematic review. Br J Gen Pract 2010;60:e128-36.

50 Hollowell J. The General Practice Research Database: quality of morbidity data. Popul Trends 1997:36-40. 